\title{
e-interview
}

\section{Peter Fonagy}

Peter Fonagy is Freud Memorial Professor of Psychoanalysis at Universty College, London, where he also trained. His interests include attachment, social cognition and mentalisation-based treatment of borderline personality disorder

If you were not a psychologist, what would you do?

As an adolescent I contemplated the law, writing thrillers and being an electrical engineer. Unfor tunately I had insufficient talent for any of these. Clinical psychology was the logical compromise.

What has been the greatest impact of your profession on you personally? Through my psychoanalysis at the Anna Freud Centre aged 17-20 years as an adolescent who was depressed and failing academically, I developed an enduring commitment to confronting unpleasant truths and understanding

\section{Do you feel stigmatised by your profession?}

Sometimes 'Freud-bashing'gets to me a bit, particularly when psychoanalytic ideas get 'discovered' and relabelled as particular types of cognition.

\section{What are your interests outside} of work?

Reading history books, skiing and watching my son play rugby.

Who was your most influential trainer, and why?

Joseph Sandler, a psychoanalyst who could state psychoanalytic ideas with remarkable clarity.

\section{Which publication has influenced} you most?

Sir Michael Rutter's papers because of their scholarship, reflectiveness and sophistication. His early book on maternal deprivation simultaneously convinced me of the

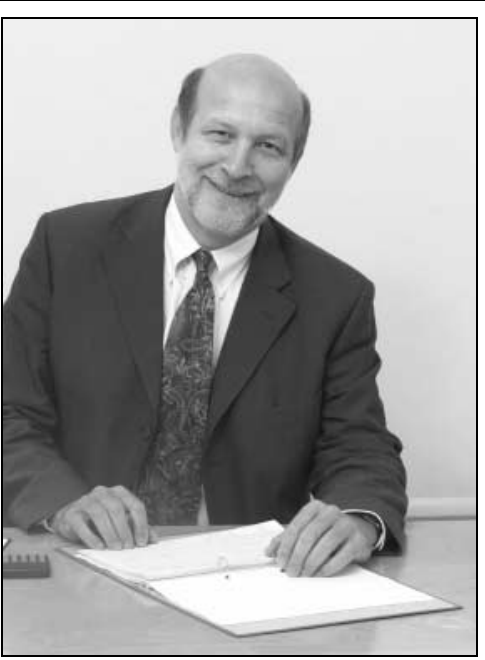

importance of attachment theory and the importance of gathering compelling empirical evidence to objectively evaluate cherished beliefs.

What part of your work gives you the most satisfaction?

Collaborating with colleagues in creating innovative treatment approaches, designing joint projects and writing as a team.

\section{What do you least enjoy?} Travelling.

\section{What is the most promising} opportunity facing the profession?

The rapid development of the brain sciences and genetics which increasingly allow (and require) us to address complex psychological questions previously ruled out of bounds by the limitations of empirical psychology.

\section{What is the greatest threat?}

'Short-termism', cheap illusory answers to fundamental social and psychological problems. 'Scientism' masquerading as science.
What is the most important advice you could offer to a new trainee? That personal experience is the basis of earning to work with distressed people, rarely papers and even more exceptionally, books.

Do you think psychiatry is brainless or mindless?

In its practice, psychiatry is very far from mindless. The contempt that some branches of medicine have for the mind may tempt some psychiatrists to minimise the importance of social determinants of psychiatric disorder and promote a peculiar and untenable 'biological approach'. It is unlikely that timeless social problems such as the neglect or maltreatment of children will ever be adequately addressed by physical treatments alone. To be effective, psychiatry has to concern itself with human intentionality.

\section{What single area of psychiatric} practice is most in need of development?

Implementation of findings from developmental psychopathology to create complex programmes of prevention.

What single area of psychiatric research should be given priority? The evaluation of child psychiatric treatments in general and interventions for emerging personality disorders in particular. Personality disorders take up a lot of resources across the healthcare system; we are not very good at treating them in adulthood. Surely, the case here for genetically informed prevention research must be irresistible.

\section{How would you like to be} remembered?

As a psychoanalyst who was committed to evidence-based practice.

Dominic Fannon

doi: $10.1192 /$ pb.bp.107.017053 